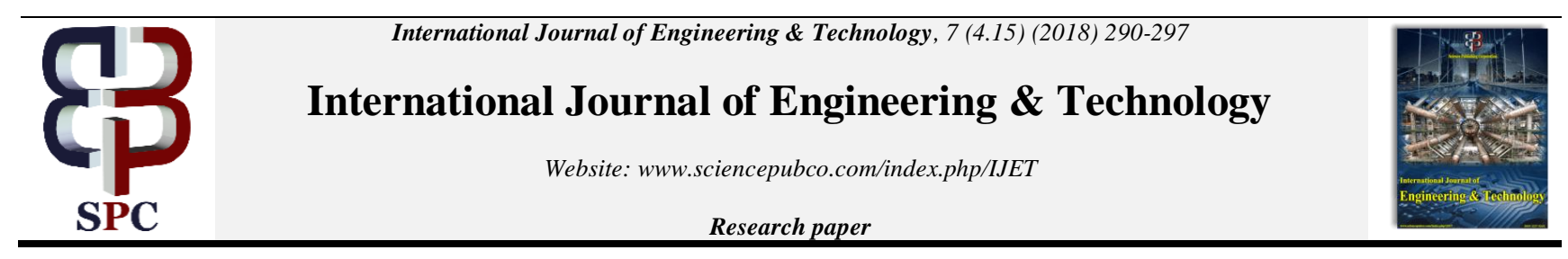

\title{
Optimum Tilt Angles for PV Modules in a Semi-Arid Region of the Southern Hemisphere
}

\author{
Pierre E Hertzog ${ }^{1}$ and Arthur J Swart ${ }^{2}$ \\ ${ }^{1,2}$ Central University of Technology \\ *Corresponding Author E-mail:phertzog@cut.ac.za
}

\begin{abstract}
It is essential to repeat a test of a given construct in research in order to underpin knowledge, support validity and enable its application in other contexts. The purpose of this article is to present repetitive test results validating the optimum tilt angle of a stationary PV module that was installed in a semi-arid region of South Africa. An experimental design incorporating a two-year longitudinal study is used. The results for 2016 and 2017 reveal that a PV module with a tilt angle of Latitude plus $10^{\circ}$ yielded the highest output power for winter months, while a PV module with a tilt angle of Latitude minus $10^{\circ}$ yielded the highest output power for summer months. However, for both years, a tilt angle set to the Latitude angle of the installation site yielded the highest overall average output power (60.02 Wh per day). It is therefore recommended to install stationary PV modules at a tilt angle equal to the Latitude of the installation site for a semiarid region in the southern hemisphere.
\end{abstract}

Keywords: Installation; energy yield; energy monitoring; tilt angle

\section{Introduction}

"On the other hand, one factor helps us that no other liberation struggle in this region could count on - our liberation front is characterized by relatively highly developed class forces, tested in political struggles" [1]. These words by Joe Slovo, a late South African politician, point to the invaluable concept of testing. For many years South Africa (SA) faced social injustice and racial discrimination from a political standpoint, which finally ended in 1994 with the fall of apartheid. This was achieved through many struggles using a liberation front that was tried and tested over many years. Repetitive testing of a given construct in research is equally important, as it underpins, or even reconstructs knowledge, supports validity and enables its application in other contexts.

Research can either reinforce or reconstruct knowledge, where the outcome must be communicated to others [2]. Obviously, information immersion would result with dull testing, lead-ing to outright legitimacy. Information immersion is characterized as "the point in information gathering when no new extra information are discovered that creates parts of a theoretical class" and guarantees the accomplishment of dependability [3]. Outright legitimacy requires that information be completely legitimate the majority of the time [4]. In this manner, when redundant testing yields similar outcomes over a delayed timeframe, at that point abso-lute legitimacy results. This is especially vital when considering the impact of climate change on the production of electrical energy from renewable energy systems.

Climate change has resulted in the rise of atmospheric temperature and a modified pattern of precipitation and evapotranspiration, which has directly led to alteration of regional hydrological cycles [5]. It has furthermore forced a shift in electrical energy pro- duction [6], with more emphasis being placed on improving efficiency while reducing losses of renewable energy systems. One type of efficiency, being the conversion efficiency, is affected by the installation of a PV module [7], and relates to the percentage of time in which a PV module produces more than $15 \%$ of its peak output power within an 8-hour period. Repetitive testing, of not only the conversion efficiency, but also of other variables associated with renewable energy systems under ever-changing environmental conditions must be maintained, so as to either strengthen or reconstruct previously published literature in this field.

The motivation behind this article is to introduce tedious test outcomes validat-ing the ideal tilt edge of a stationary PV module that was in-slowed down in a semi-parched area of South Africa. Past research has given an account of the effect of various tilt edges on the yield intensity of a stationary PV module for various long periods of the year. For exam-ple, Hertzog and Swart gave an account of the late spring period of 2014-2015 [8] and on the winter season of $2015[9,10]$. For the summer season, they found that a tilt angle lower than Latitude of the installation site yielded the highest output power, while for the winter season the tilt angle had to be higher than Latitude. However, no repetitive test results for a prolonged period of time exist for this semi-arid region of SA, which falls in the southern hemisphere.

The article will firstly cover the importance of tilt angles for PV module installations, and then outline the study context. The experimental setup follows along with the research methodology. The quantitative data that was obtained is presented in a number of figures along with pertinent discussions. 


\section{Tilt angle importance}

The tilt angle of a PV module is defined as the number of degrees that its surface is inclined from the horizontal plane (e.g. surface facing directly upwards equals $0^{\circ}$ while a surface facing the horizon equals $90^{\circ}$ ) [11]. Alternative it is stated that "The tilt angle is defined as the slope angle at which solar panels are mounted to face the sun" [12]. These definitions propose that a PV module ought to be introduced with the goal that its glass surface faces the sun for a large portion of the day. In a perfect world, it ought to be tilted opposite to the sun at twelve $(12 \mathrm{pm})$, which likewise impacts on its introduction point [7]. Figure 1 demonstrates the situation of the tilt point in connection to the level plane. In the event that a PV module must be introduced with its glass surface confronting specifically upwards into the sky, at that point its tilt edge will rise to $0 \square$. Moving the highest point of the PV mod-ule far from the level plane, while keeping the base sta-tionary on the flat plane, will result in a particular tilt edge. A basic protractor, or cell phone application, for example, Bubble Level, can be utilized to gauge this tilt edge. Basically putting the cell phone on the back or glass surface while moving the highest point of the PV module far from the even plane will give a perusing.

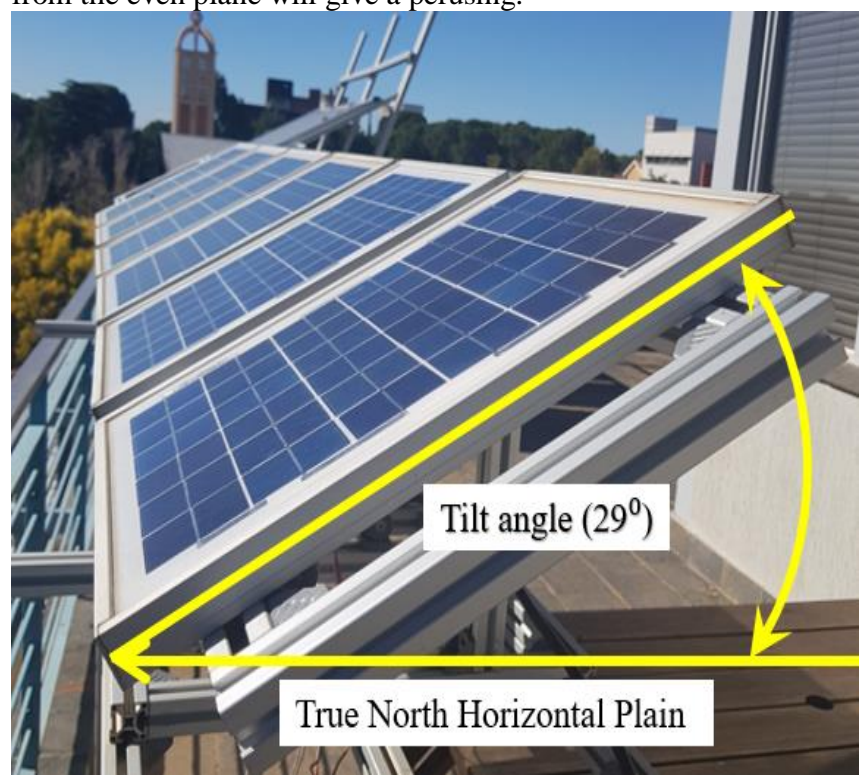

Fig. 1: Tilt angle position

Research by Heywood and Chinnery recommends utilizing a tilt edge which is either equivalent to the Latitude point of the establishment site, or then Latitude in addition to $10^{\circ}$ or short $10^{\circ}$ for the southern side of the equator [13]. A far reaching study led in the southern half of the globe by Cronemberger [14] watched the accessibility of sunlight based potential yield in 78 Brazilian urban communities situated between Latitude points of $0^{\circ}$ and $30^{\circ} \mathrm{S}$. The outcomes showed that just 8 urban communities had an ideal tilt point that is equivalent to Latitude, while the other 70 urban areas ideal tilt edges changed somewhere in the range of $1.5^{\circ}$ and $9.3^{\circ}$ or more Latitude. Asowata et al. [15] found that, for a stationary PV module in SA, a tilt edge of Latitude in addition to $10^{\circ}$ yielded the most astounding normal yield control during the time for a contamination serious zone. Hertzog and Swart [8] decided the influ-ence that distinctive tilt points applied on the yield control yield of a stationary PV module in a semi-dry locale of SA. They presumed that a tilt edge of Latitude in addition to 10 yielded the most noteworthy yield control from a PV module amid the winter season, while Latitude less 10 degree yielded the most noteworthy yield control for the late spring season. However, the results were limited to a few months for 2015 and 2016. Repetitive testing, over a prolonged period of time, to determine which tilt angle contributes to the highest average yield of output power from a stationary PV module under varying environmental conditions would contribute to absolute validity.

\section{The study context}

The examination site is restricted to the focal district of SA, called the Free State Province, which is delegated a semi-parched locale. This territory has a normal every day radiation of somewhere in the range of 4.5 and $7 \mathrm{kWh} / \mathrm{m} 2$, along these lines having the potential for a superb sun based vitality yield [16]. The commonplace capital of the Free State Province is Bloemfontein, where the primary grounds of the Central University of Technology (CUT) is found. The every day normal worldwide flat radiation for this establishment site is roughly $5.15 \mathrm{kWh} / \mathrm{m} 2 /$ day [16], with a normal yearly precipitation of around $550 \mathrm{~mm}$ [17]. The winter season is extremely dry with dust storms that happen frequently among May and August of every year.

The Faculty of Engineering and Information Technology is situated on the main campus of CUT, with a number of laboratories and research facilities. One such facility has a fourth-floor balcony facing northwards, with unobstructed views of the sun. This ensures that direct beam radiation of the sun is received by the stationary PV modules throughout the day. The exact Latitude and Longitude coordinates of this balcony is $29^{\circ} 07^{\prime} 16.7^{\prime \prime} \mathrm{S}$ and $26^{\circ} 12^{\prime} 58.2^{\prime \prime} \mathrm{E}$, which serves as the research installation site for three identical $10 \mathrm{~W}$ PV modules used in the experimental setup.

\section{Experimental setup}

The exploratory setup involves three indistinguishable PV frameworks, each with a $10 \mathrm{~W}$ polycrystalline PV module, a 5 A sun oriented charger, a $20 \mathrm{Ah}$ lead corrosive gell battery and $2 \times 5 \mathrm{~W}$ LED lights (a square graph is appeared in Figure 2). These three PV modules were mounted on an aluminum structure that was anchored to the fourth floor gallery of the ETB Building at CUT. At first, all the PV modules were in-slowed down at a tilt point equivalent to Latitude of the establishment site $\left(29^{\circ}\right)$ for alignment purposes. This was improved the situation a time of multi week, after which a coefficient of variety (1.4\%) was resolved between the yield forces of the indistinguishable modules. This alignment procedure (itemized in [18]) was done to help the legitimacy and dependability of resulting estimations, and to guarantee that each of the three frameworks star duced a similar yield control when all factors were kept consistent. Once the adjustment procedure was finished, the three PV modules were set to three particular tilt edges.

These tilt points were gotten from work done by Heywood and Chinnery and depends on the Latitude of the establishment site $[19,20]$. Latitude minus $10^{\circ}\left(\varphi-10^{\circ}\right)$, Latitude $(\varphi)$ and Latitude plus $10^{\circ}\left(\varphi+10^{\circ}\right)$ was used. In this way, the tilt angle becomes the only variable that would be different between the three identical PV systems. When studying specific effects in an environment, it is important for the researcher to keep a certain set of variables constant while changing only one variable at a time [21].

The three identical PV systems were connected to an energy monitoring system that was developed by the researchers [22]. It consisted of a logging interface circuit, an Arduino Mega microcontroller board and a computer-driven software program, called LabVIEW. The following sections explain this in more detail.

\section{Logging interface circuit and Arduino}

A logging interface circuit was designed for power conditioning as the nominal output voltages from PV modules used in this study can vary between 0 and $21 \mathrm{~V}$ (open circuit voltage). Voltage, current and temperature readings were limited to below $5 \mathrm{~V}$ in order to protect the analog to digital converters on the Arduino Mega microcontroller. Voltage reduction was achieved by using a voltage divider circuit with resistors having a $1 \%$ tolerance value. The current was calculated in the LabVIEW software by measuring the voltage across two $12 \mathrm{Ohm}$ parallel resistors (each with a toler- 
ance value of $1 \%$ ) and then dividing it by $12 \mathrm{Ohm}$ (see Figure 3 for R7 - R12). The temperature of the PV modules was measured using a $10 \mathrm{k} \Omega$ thermistor in series with a $10 \mathrm{k} \Omega$ resistor to form another voltage divider circuit. Current, voltage and temperature readings are then relayed to the LabVIEW software on the PC via a USB cable.

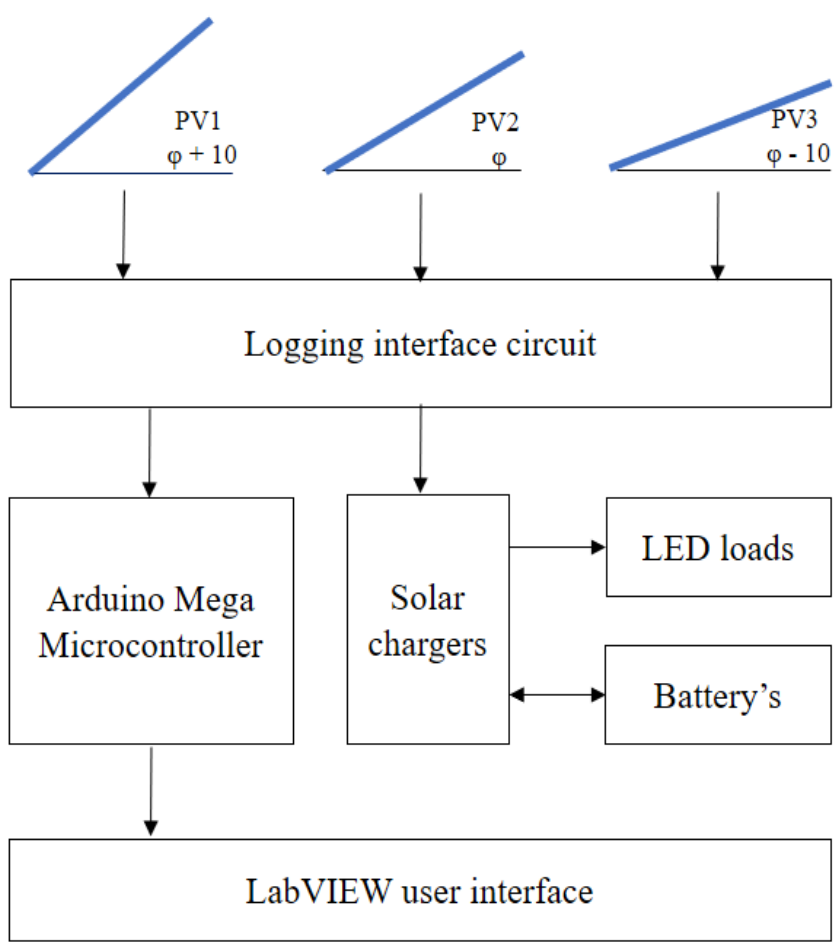

Fig. 2: Experimental setup

\section{LabVIEW Measurements}

LabView (Laboratory Virtual Instrument Engineering Workbench) has a visual programming enviorment that is used by scientists and engineers around the world [23]. In this research study, it is used as an instrument that displays instantaneous measured data, while recording it simultaneously. Data (which includes temperature, current and voltage measurements) is received from an Arduino microcontroller and shown on the user interface. An analog read function is invoked in LabVIEW to read analog data from the Arduino board. In order to compensate for the reduced voltages from the logging interface circuit, calibration factors were used. The calibration factors for voltage and current can be seen as $\mathrm{H}$ and $\mathrm{G}$ in the LabVIEW interface (see Figure 4), and can be adjusted at any time during the operation of the program, enabling real-time calibration. High-frequency components caused by the Arduino's analog read circuit is filtered out by a low pass Butterworth filter. The calculated values of power (using the measured voltage and current values) is also shown on the LabVIEW user interface (see Figure 4 - top right outside of each graph). All values are stored in a matrix and eventually written to a text file for further analysis in MS EXCEL.

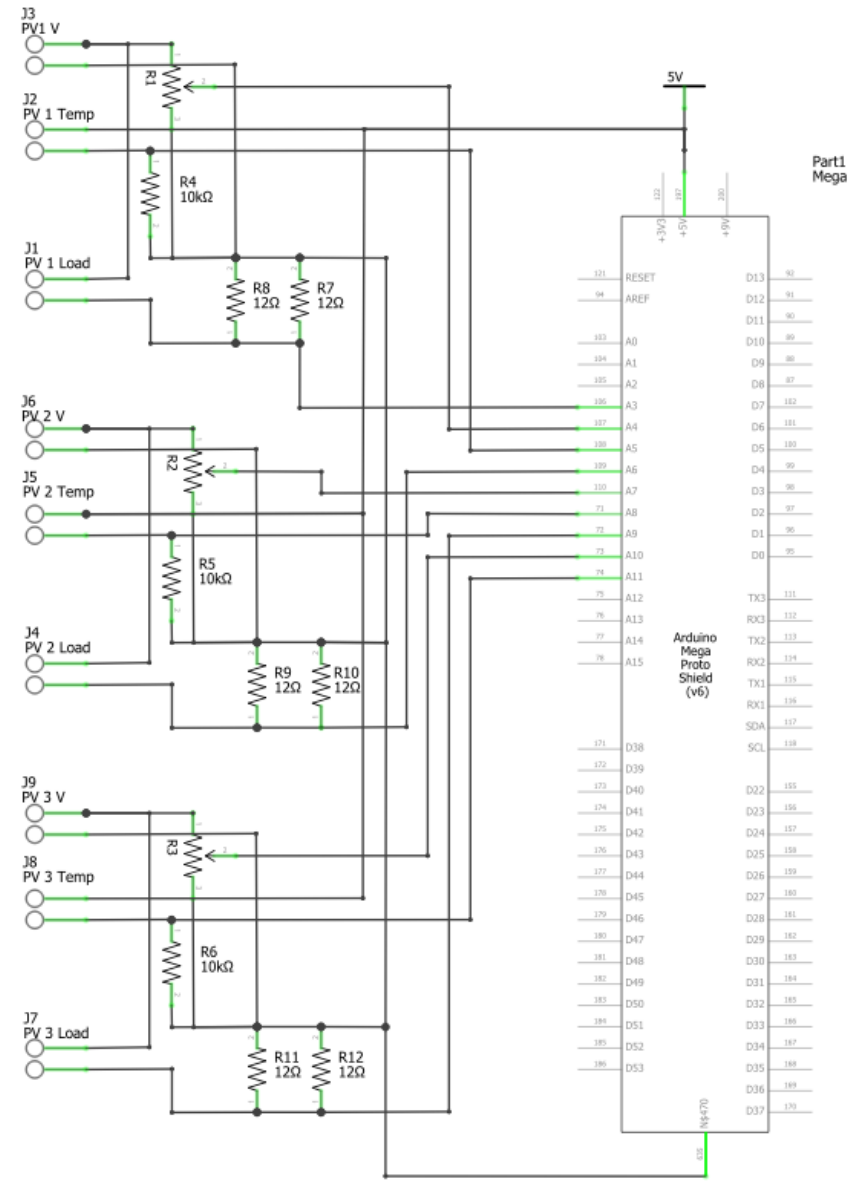

Fig. 3: Logging interface circuit [9]

Two methods was used to determine the performance of the PV modules on a daily basis. In the first method, the percentage of time that the modules produced more than a predefined power value were calculated ( $3 \mathrm{~W}$ for this study), and stored in a text file. In the second method, the no. of Watt hours which were generated by the modules were recorded and stored. The Watt hours is calculated by multiplying the time, epitomised by a number of samples, with the mean power produced per sample. In this way, an instantaneous $\mathrm{Wh}$ value is calculated for a specific number of samples. This Watt hours measurement is showed on LabVIEW user interface with the accumulated Wh for the day stored in a text file (see $\mathrm{F}$ in Figure 4). The following information can be observed in the LabVIEW user interface [9]:

- instantaneous values of power for each module in graph form (point C),

- instantaneous values of current for each module in graph form (point D),

- instantaneous values of voltage for each module in graph form (point E),

- the tilt angle of the PV modules (point $\mathrm{J}$, the value of $30^{\circ}$ that was used for calibration purposes is shown in the figure),

- current calibration factors (point $\mathrm{G}$ ) and voltage calibration factors (point $\mathrm{H}$ ),

- $\quad$ accumulated $\mathrm{Wh}$ value for each module per day (point F),

- number of samples above a specified power level (point B), and

- the total number of samples for a given day (point A).

The sampling interval was set to 10 seconds over a 12 -hour period. The LabVIEW software program automatically determines the number of total samples based on this criteria, which in this case equates to 4320 samples for the file. The date stamp is also visible showing when the program started to record data (in this case it was $28 \quad$ February 2018 at 07:05 am). 


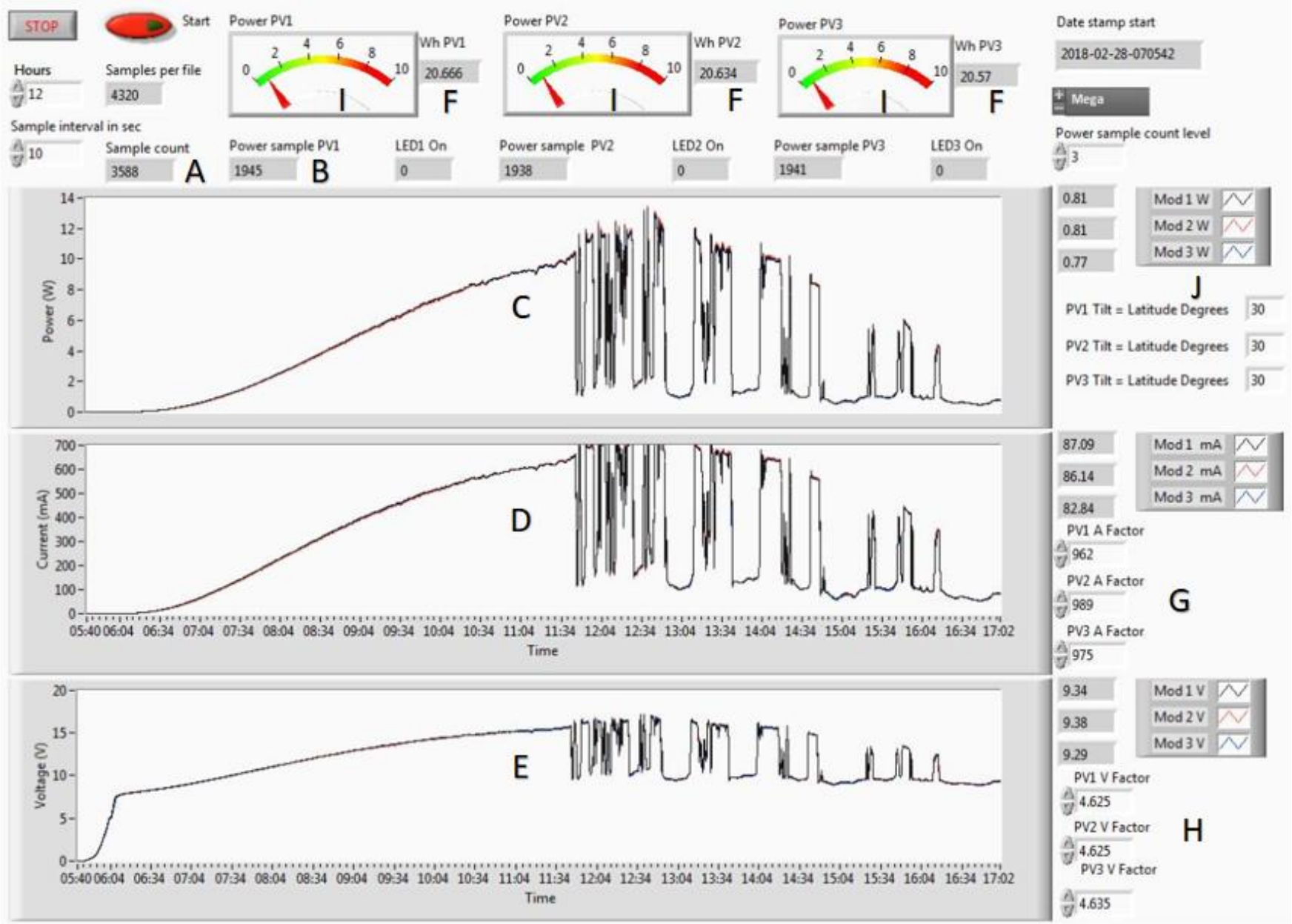

Fig. 4: LabVIEW user interface

\section{Research Methodology}

In this study an experimental research design is used to examine causality, which is defined as a relationship between two events, cause and effect [24]. In this regard, the cause would be adjusting the tilt angle of two PV modules to Latitude plus $10^{\circ}$ and Latitude minus $10^{\circ}$, while keeping the third PV module at Latitude. The effect would be determining the difference in the yield of output power from these three modules.

Longitudinal studies are studies in which the outcome variable is measured repetitively [25]. In this study, the outcome variable is the impact that different tilt angles have on the yield of output power from identical PV modules. This is done for a two-year period $(2016$ - 2017). Each additional wave of data (or data from each successive year) from a longitudinal study increases the reliability and precision of measuring change and adds power to the results [26]. The system was installed in 2015, when the project was conceptualized. This included a setup and calibration stage. Since then, continuous data has been collected from the practical setup giving rise to this longitudinal study. During this period, the three identical PV modules had a similar introduction points, a similar sort of bat-tery, a similar kind of sun oriented charger, and were presented to the same natural conditions. Just a single variable was unique, in particular the tilt edge. Data covering the entire year (January through December) is presented in two graphs (one for 2016 and one for 2017). The Wh per day and the total amount of samples that were above a predefined power level were recorded and analysed, giving rise to only quantitative data. This data is presented in the following section which includes a Pearson correlation between these data sets.

\section{Results and discussion}

The first method of analysis required obtaining the average number of samples where the output power of the $10 \mathrm{~W}$ PV modules exceeded $3 \mathrm{~W}$ (predefined power level). Fig. 5 presents the average samples per month above $3 \mathrm{~W}$ for 2016 and 2017. The highest yield of output power was found at Latitude plus $10^{\circ}\left(\varphi+10^{\circ}\right)$ for the winter season (April to August) and Latitude minus $10^{\circ}(\varphi-$ $10^{\circ}$ ) for the summer season (October to February). This correlates with work done by Cronemberger [14] and Asowata et al. [15], as discussed in section 2 . The transition between summer and winter can be seen in March where the output of all three tilt angles is similar. Similarly, the transition between winter and summer can also be observed in the spring month of September.

The second method of analysis required obtaining the average $\mathrm{Wh}$ per day for the years 2016 and 2017. This is shown in Figure 6. The similarity between the three different tilt angles is once more observed for March and September, which indicates the spring and autumn equinox. Although weather conditions had an enormous influence on the amount of output power produced; the results showed that a tilt angle of $\varphi+10^{\circ}$ produced the highest yield for winter and $\varphi-10^{\circ}$ for summer. These results correlate well with results of previous studies, over shorter periods, by the authors and other researchers $[9,18,27]$. 


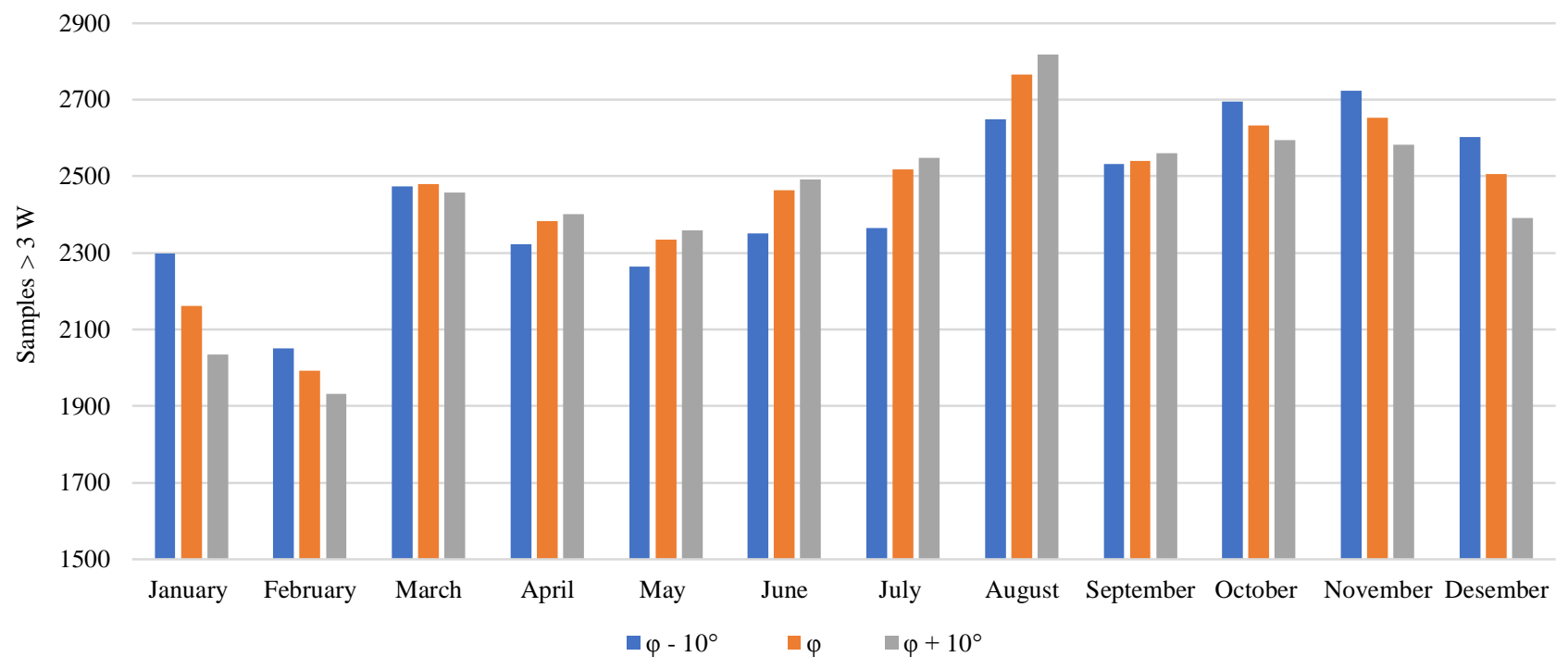

Fig. 5: Average number of samples per month where the output power exceeded $3 \mathrm{~W}$ for 2016 and 2017

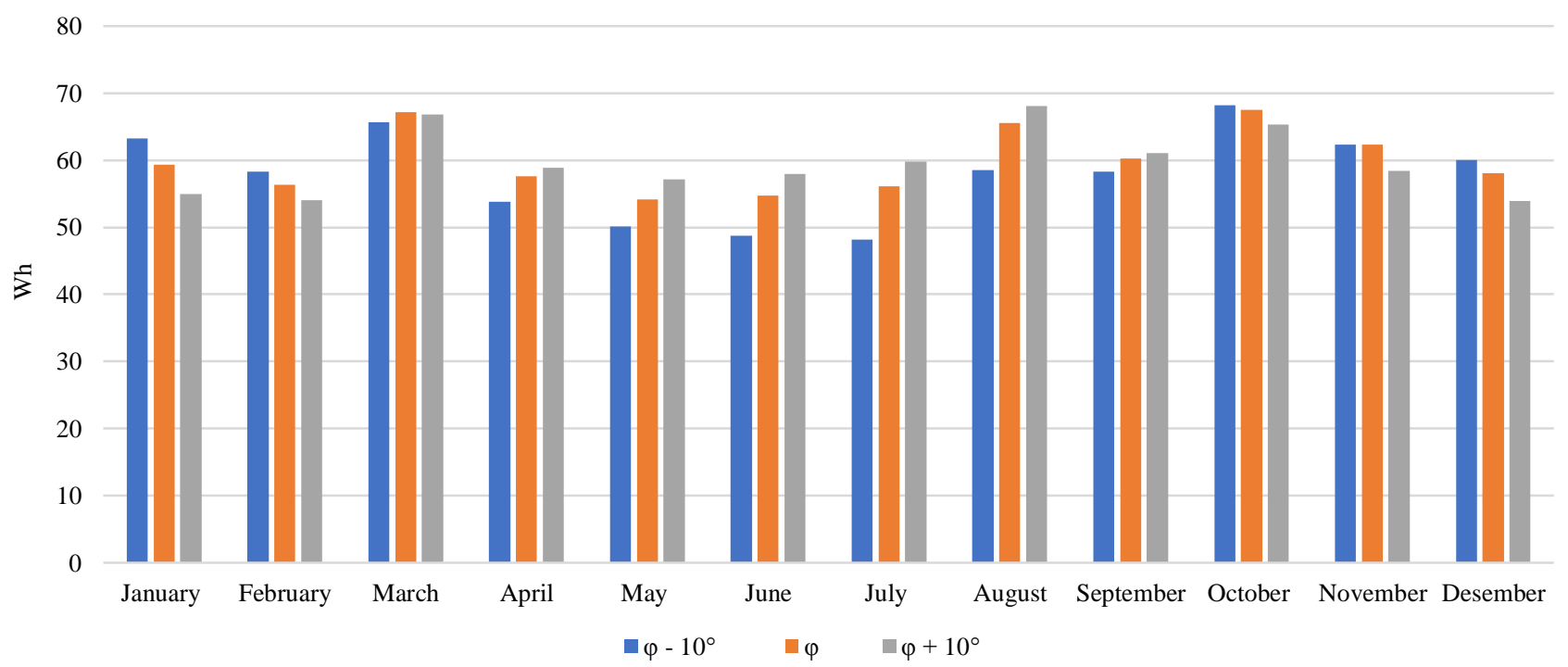

Fig. 6: Average Wh per month for 2016 and 2017

A more detailed graphical representation of Figure 6 is shown in Figure 7, and Figure 8 was the average yield of output power per day (in Wh) is shown for 2016 and 2017 respectively. A third order polynomial function was used to insert a trend line onto the graph for each of the three tilt angles. These trend lines indicate that the Latitude minus $10^{\circ}$ tilt angle (dotted blue line) yielded the highest output power for November through February, while the Latitude plus $10^{\circ}$ tilt angle (dotted grey line) yielded this result for April through September.

The presence of many downward "spikes" that exist below $40 \mathrm{Wh}$ is indicative of cloud movement, which impacts severely on the yield of output power for all three tilt angles. Bloemfontein is a summer rainfall area with less cloud movement during the winter months [28]. This is confirmed in Figure 7 where only one significant downward "spike" is evident on 14 June 2016, with no other interruptions in direct beam radiation visible between 17 May and 23 July 2016.

For 2017, this is evident between 15 May and 28 July 2017 where only two significant downward "spikes" exist (27 June and 14 July 2017) pointing to direct beam radiation due to cloud movement. The similarity between the three tilt angles is also discerned from the three trend line which crosses each other in March (autumn equinox) and early October (just after the spring equinox) for both 2016 (Figure 7) and 2017 (Figure 8). The overall shape of the Wh graphs also aligns well with the annual solar radiation curve, which has a trough in winter months and a peak in summer months.

Noteworthy, for both years, is the period during which the peak Wh per day were recorded. This corresponds to February / March for both years where a peak value of almost $90 \mathrm{Wh}$ was recorded. 


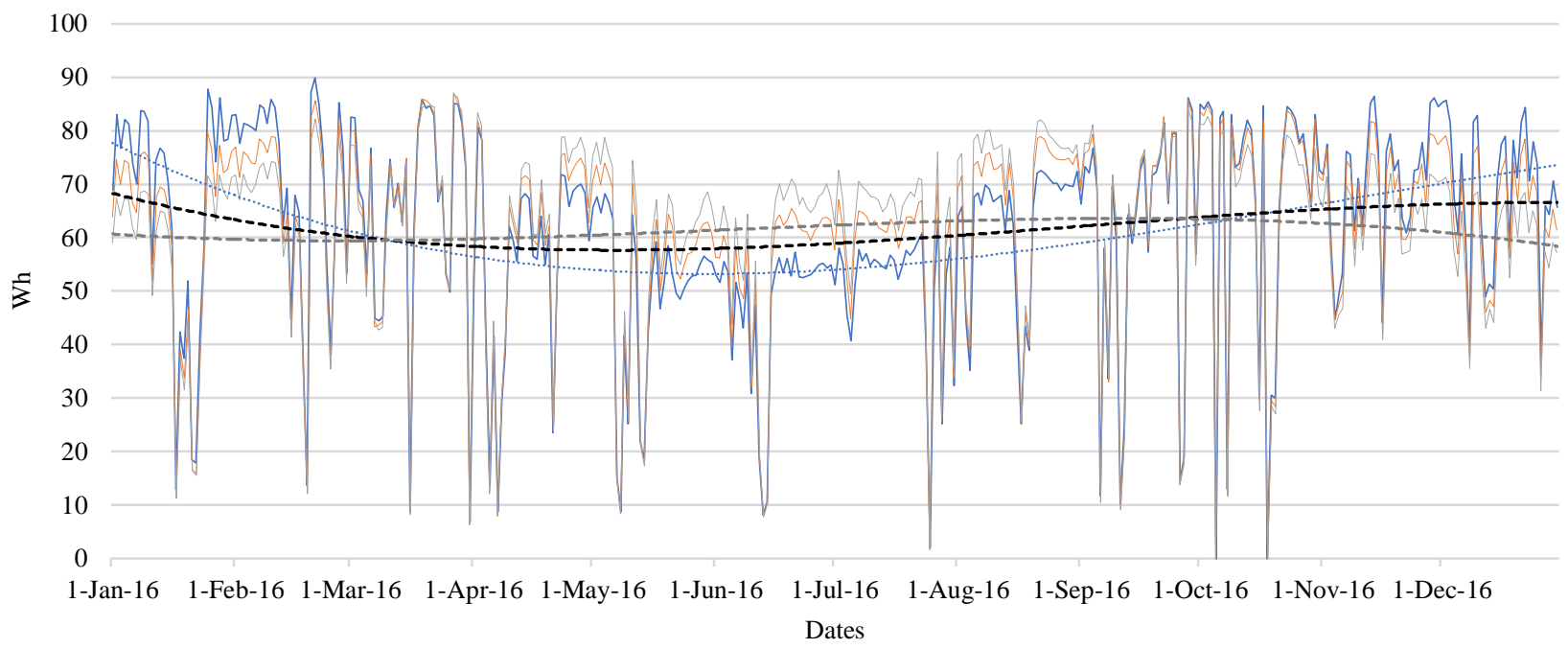

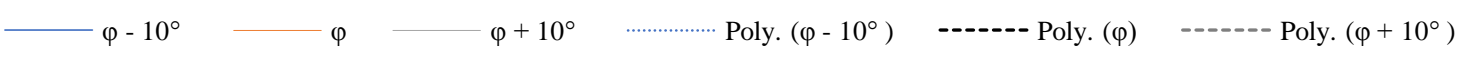

Fig. 7: Average Wh per day over in 2016

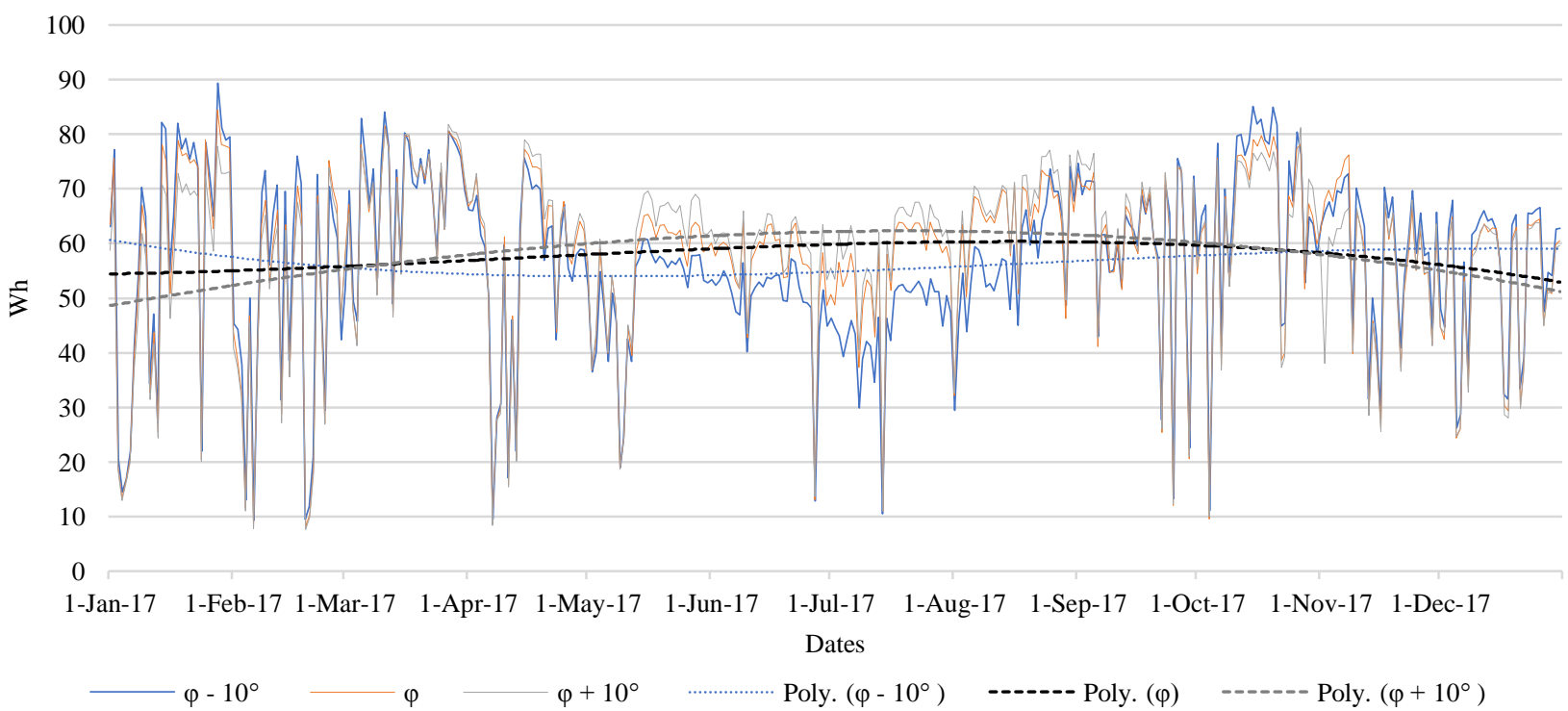

Fig. 8: Average Wh per day over in 2017

Table 1 highlights exact values for Wh produced in 2016 and 2017 for each month. Noteworthy is the fact that the results show a variation from year to year. In February 2016, $71 \mathrm{Wh}$ was produced by the Latitude minus $10^{\circ}$ tilt angle. However, in February 2017 , this same tilt angle only produced $46 \mathrm{Wh}$. This speaks to a considerable variety that can significantly affect the supportability of a PV framework. This variety can be added to various climate and barometrical conditions [29] and environmental change. These variations must be considered by system designers and developers of simulation software packages, who should factor in a higher percentage "unknown variable" due to changing environmental conditions. The average overall Wh produced for 2016 and 2017 is shown in Fig. 9, which indicates that the PV module that was mounted at Latitude produced the highest overall average amount of energy (60.02 Wh per day) for 2016 and 2017. This correlates well with literature discussed in section two of this article [13]. However, the percentage difference between the tilt angles is less than $1.9 \%$. This percentage difference may increase proportionally when the size of the PV module is increased. In this study, $10 \mathrm{~W}$ PV modules were used. Using $200 \mathrm{~W}$ PV modules may yield a larger difference.

Table 1: Month to month comparison of Wh produced at different tilt angles

\begin{tabular}{|c|c|c|c|c|c|c|c|c|c|c|c|c|c|c|c|c|c|c|c|c|c|c|c|c|}
\hline & $\frac{0}{\stackrel{1}{ \pm}}$ & 골 & $\begin{array}{l}0 \\
\frac{1}{1} \\
\frac{1}{0} \\
1\end{array}$ & $\frac{1}{\frac{1}{0}}$ & 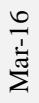 & 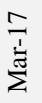 & $\frac{0}{\frac{1}{\alpha}}$ & $\frac{\sqrt{1}}{\frac{1}{2}}$ & 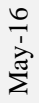 & 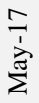 & 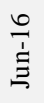 & $\stackrel{\text { I }}{\Xi}$ & $\frac{0}{\frac{1}{\Xi}}$ & $\frac{\Xi}{\Xi}$ & $\begin{array}{l}0 \\
\frac{1}{1} \\
0 \\
3 \\
z\end{array}$ & $\frac{\sigma}{\sigma_{0}^{\prime}}$ & $\frac{0}{1}$ & 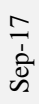 & $\frac{0}{\frac{1}{0}}$ & $\frac{\pi}{\frac{1}{0}}$ & $\begin{array}{l}0 \\
\frac{1}{1} \\
0 \\
z\end{array}$ & $\begin{array}{l}n \\
\frac{1}{2} \\
z\end{array}$ & 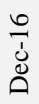 & $\frac{1}{\vdots}$ \\
\hline $\begin{array}{r}\varphi- \\
10^{\circ}\end{array}$ & 66 & 60 & 71 & 46 & 66 & 66 & 56 & 52 & 50 & 51 & 48 & 50 & 51 & 45 & 63 & 54 & 60 & 56 & 72 & 65 & 70 & 54 & 69 & 52 \\
\hline$\varphi$ & 61 & 58 & 66 & 46 & 65 & 69 & 58 & 57 & 54 & 54 & 53 & 56 & 57 & 55 & 67 & 64 & 61 & 59 & 71 & 64 & 67 & 57 & 64 & 52 \\
\hline
\end{tabular}


In further validation of the results, a Pearson correlation was used to determine the correlation of the samples above $3 \mathrm{~W}$ and the $\mathrm{Wh}$ that was produced per day by the modules. Results indicated that a strong correlation ( $\mathrm{p}=0.96$ or higher) exists between the 2016 and 2017 results. It can thus be concluded that the two methods of analysis used in this study are both valid and reliable in comparing PV module parameters related to output power yield.

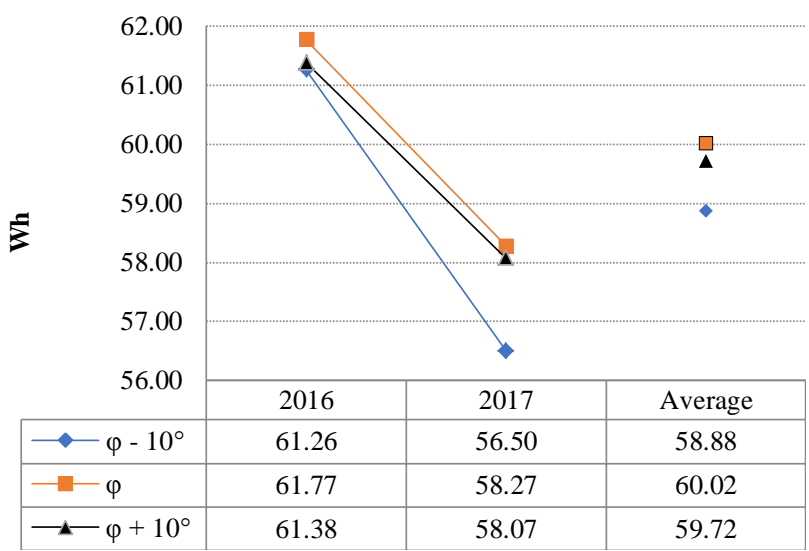

Fig. 9: Average Wh per day for 2017 and 2018

\section{Conclusion}

The objective of this research was to show repetitive results validating the optimum tilt angle for the installation of stationary PV modules in semi arid region of South Africa, thereby contributing to absolute validity. The results of two years 2016 and 2017 were considered. Results showed that the highest yield of output power was always $\varphi+10^{\circ}$ for the winter season and $\varphi-10^{\circ}$ for the summer season. This correlates well with published literature. The PV module that was mounted at a tilt angle equal to Latitude produced the highest overall average output power $(60.02 \mathrm{Wh}$ per day) for the two years. A clear year to year variance in output power produced by PV modules was observed. This may be attributed to changing environmental conditions and climate change that must be factored into the design and simulation of PV systems that are used for forecasting and installation purposes. However, the overall results were consistent for the two year period regarding the influence that diffferent tilt angles have on the output power produced by identical PV modules, thereby contributing to the validity of the practical setup and the reliability of the data. A key recommendation of this research is to determine the proportionate percentage difference between the three tilt angles when using larger identical PV modules.

\section{References}

[1] Brainy Quote. (2018, 19 March). Homepage. Available: http://www.brainyquote.com/quotes/

[2] M. Byrne, "Disseminating and presenting qualitative research findings," AORN journal, vol. 74, pp. 731-732, 2001.

[3] J. J. Francis, M. Johnston, C. Robertson, L. Glidewell, V. Entwistle, M. P. Eccles, et al., "What is an adequate sample size? Operationalising data saturation for theory-based interview studies," Psychology and Health, vol. 25, pp. 1229-1245, 2010.

[4] S. Cai, B. Gallina, D. Nyström, and C. Seceleanu, "Towards the verification of temporal data consistency in Real-Time Data Management," in Modelling, Analysis, and Control of Complex CPS (CPS Data), 2016 2nd International Workshop on, 2016, pp. $1-6$.

[5] H. Sellami, S. Benabdallah, I. La Jeunesse, and M. Vanclooster, "Climate models and hydrological parameter uncertainties in climate change impacts on monthly runoff and daily flow duration curve of a Mediterranean catchment," Hydrological sciences journal, vol. 61, pp. 1415-1429, 2016.
[6] A. A. S. de la Nieta, R. F. Martins, T. A. Tavares, J. C. Matias, J. P Catalão, and J. Contreras, "Short-Term trading for a photovoltaic power producer in electricity markets," in Power \& Energy Society General Meeting, 2015 IEEE, 2015, pp. 1-5.

[7] A. J. Swart and P. E. Hertzog, "Validating the acceptance zone for PV modules using a simplified measuring approach," presented at the ECTI-CON, 13th International Conference on Electrical Engineering, Electronics, Computer and Information Technology, Chiang Mai, Thailand., 2016.

[8] P. E. Hertzog and A. J. Swart, "Determining the optimum tilt angles for PV modules in a semi-arid region of South Africa for the summer season," presented at the SATNAC 2015, Arabella, Hermanus, Western Cape, 2015.

[9] P. E. Hertzog and A. J. Swart, "Validating three different tilt angles for PV modules in a semi-arid region " in International Conference on Innovative Research and Development (ICIRD) 2018, Klong Luang, Thailand, 2018.

[10] P. E. Hertzog and A. J. Swart, "Validating the optimum tilt angle for PV modules in the central region of South Africa for the winter season," presented at the ECTI-CON, 13th International Conference on Electrical Engineering, Electronics, Computer and Information Technology, Chiang Mai, Thailand. ISBN: 978-1-467-39749-0, 2016.

[11] A. K. Sidibe, M. Ghogho, C. El Amrani, and M. Faquir, "A comparative study of simple clear sky irradiance models," in Electrical and Information Technologies (ICEIT), 2016 International Conference on, 2016, pp. 113-117.

[12] P. Yadav, N. Kumar, and S. Chandel, "Simulation and performance analysis of a $1 \mathrm{kWp}$ photovoltaic system using PVsyst," in Computation of Power, Energy Information and Commuincation (ICCPEIC), 2015 International Conference on, 2015, pp. 03580363.

[13] S. Armstrong and W. G. Hurley, "A new methodology to optimise solar energy extraction under cloudy conditions," Renewable Energy, vol. 35, pp. 780-787, 2009.

[14] J. Cronemberger, E. Caamaño-Martín, and S. V. Sánchez, "Assessing the solar irradiation potential for solar photovoltaic applications in buildings at low latitudes-Making the case for Brazil," Energy and Buildings, vol. 55, pp. 264-272, 2012.

[15] O. Asowata, A. J. Swart, H. C. Pienaar, and R. M. Schoeman, "Optimizing the output power of a stationary PV panel," presented at the SATNAC 2013, Stellenbosch, South Africa, 2013.

[16] S. K. Mulaudzi, M. Muchie, and R. Makhado, "Investigation of the solar energy production and contribution in South Africa: research note," African Journal of Science, Technology, Innovation and Development, vol. 4, pp. 233-254, 2012

[17] M. N. Dingaan and P. J. Du Preez, "Grassland communities of urban open spaces in Bloemfontein, Free State, South Africa," koedoe, vol. 55, pp. 01-08, 2013.

[18] P. E. Hertzog and A. J. Swart, "Validating the optimum tilt angle for PV modules in a semi-arid region of South Africa for the winter season," in ECTI-CON 2016, Chiang Mai, Thailand, 2016.

[19] H. Heywood, "Operating experiences with solar water heating," Journal of Installation Heat Venting Energy, vol. 39, pp. 63-69, 1971.

[20] D. N. W. Chinnery, "Solar heating in South Africa," Pretoria CSIRResearch Report 248, 1981.

[21] M. J. Konings, M. T. Elferink-Gemser, I. K. Stoter, D. van der Meer, E. Otten, and F. J. Hettinga, "Performance characteristics of long-track speed skaters: a literature review," Sports Medicine, vol. 45 , pp. 505-516, 2015.

[22] P. Hertzog and A. Swart, "A customizable energy monitoring system for renewable energy systems," presented at the SAUPEC 2015, Resolution Circle Towers in Napier Road in Milpark Johannesburg, 2015.

[23] R. Bitter, T. Mohiuddin, and M. Nawrocki, LabVIEW: Advanced programming techniques: Crc Press, 2017.

[24] A. Toomela, "The ways of scientific anticipation: From guesses to probabilities and from there to certainty," in Anticipation across disciplines, ed: Springer, 2016, pp. 255-273.

[25] J. W. Twisk, Applied longitudinal data analysis for epidemiology: a practical guide, 2nd ed. New York: Cambridge University Press, 2013.

[26] T. E. Moffitt, D. W. Belsky, A. Danese, R. Poulton, and A. Caspi, "The Longitudinal Study of Aging in Human Young Adults: Knowledge Gaps and Research Agenda," The Journals of 
Gerontology Series A: Biological Sciences and Medical Sciences, vol. 0, pp. 1-6, 2016.

[27] P. Hertzog and A. Swart, "Determining the optimum tilt angles for PV modules in a semi-arid region of South Africa for the summer season," in Southern Africa Telecommunication Networks and Applications Conference (SATNAC) 2015 Kogelberg Biosphere Reserve near Hermanus, Western Cape, South Africa, 2015.

[28] Z. Mashaba, G. Chirima, J. Botai, L. Combrinck, and C. Munghemezulu, "Evaluating spectral indices for winter wheat health status monitoring in Bloemfontein using Lsat 8 data," South African Journal of Geomatics, vol. 5, pp. 227-243, 2016.

[29] F. H. Gandoman, F. Raeisi, and A. Ahmadi, "A literature review on estimating of PV-array hourly power under cloudy weather conditions," Renewable and Sustainable Energy Reviews, vol. 63 , pp. 579-592, 2016 